\title{
Dose-response relation for vascular disorders induced by vibration in the fingers of forestry workers
}

\author{
M Bovenzi, A Franzinelli, R Mancini, M G Cannavà, M Maiorano, F Ceccarelli
}

\begin{abstract}
Objectives-To study the relation between the prevalence of vascular disorders (white finger) and vibration exposure in a group of 222 forestry workers, of whom $164(73.9 \%)$ had work experience limited to antivibration (AV) chain saws only and $58(26 \cdot 1 \%)$ had operated both non-AV and $A V$ chain saws.

Methods-The chain saw operators and 195 control workers never exposed to hand transmitted vibration were interviewed with health and workplace assessment questionnaires. The diagnosis of vibration induced white finger (VWF) was made on the basis of subjective symptoms of finger blanching and the results of a cold test with plethysmographic measurement of systolic blood pressure of the finger. Vibration was measured on a representative sample of $A V$ and non-AV chain saws. Daily vibration exposure was assessed as eight hour energy equivalent frequency weighted acceleration (A(8)). A lifetime vibration dose was estimated for each of the forestry workers.
\end{abstract}

Results-The overall prevalence of VWF among the forestry workers was $23.4 \%$. The diagnosis of VWF was made in $13.4 \%$ of the forestry workers who handled only AV chain saws and in $51.7 \%$ of those who had also operated non-AV chain saws in the past. Raynaud's phenomenon was found in $2.6 \%$ of the controls. In the forestry workers, the risk for VWF showed positive increments with each increment of vibration dose, suggesting a monotonic dose-response relation. The responsiveness to cold in the digital arteries of the forestry workers was also found to increase with increasing vibration dose and severity of VWF. The estimated relation between VWF and vibration exposure showed that the expected prevalence of VWF increased almost linearly to either $A(8)$ (with exposure duration unchanged) or the number of years of exposure (with equivalent acceleration unchanged).

Conclusions-In this study of VWF among forestry workers, the estimated dose-response relation showed that if the magnitude of vibration acceleration is doubled, the total duration of exposure should be halved to produce an equivalent effect. On the basis of the assessment of vibration exposure, the estimated risk for VWF in the study population was found to be lower than that predicted by the inter- national standard ISO 5349. These findings suggest a revision of the risk estimates for VWF currently provided by ISO 5349.

(Occup Environ Med 1995;52:722-730)

Keywords: hand transmitted vibration; risk model; vibration white finger

Excessive exposure to harmful vibration from hand held powered tools can give rise to a vasospastic disorder in the fingers of users called vibration induced white finger (VWF). Epidemiological studies conducted in the late 1960 s and early 1970 s reported high occurrence of VWF (40\%-90\%) among forestry workers who used chain saws. ${ }^{1-11}$ Subsequently, a gradual decrease in the prevalence and incidence of VWF was found in several surveys of chain saw operators. ${ }^{12-15}$ This finding was ascribed to both the introduction of antivibration (AV) chain saws in forest work and administrative measures curtailing the duration of saw use each day. ${ }^{12-15}$

The results of some studies of forestry workers conducted between 1968 and 1975 have been used to assess quantitatively the relation between vibration exposure and the occurrence of VWF. ${ }^{681116-20}$ Taking into account exposure and epidemiological data from studies of forestry workers, grinders, rock drillers, and miners a relation between the magnitude of frequency weighted acceleration of vibrating tools and the latent interval for VWF-that is, the duration of exposure before the appearance of the first finger blanching attack-was derived by Brammer. ${ }^{21}$ The estimated dose-response relation was then included in the annex $A$ to the international standard ISO 5349. ${ }^{22}$ It should be noted that in the groups of forestry workers investigated in the early 1970s the risk of developing VWF was very high because of the great magnitudes of frequency weighted acceleration produced by non-antivibration (non-AV) chain saws $\left(10-25 \mathrm{~m} \cdot \mathrm{s}^{-2}\right) .^{23}$ This is confirmed by the short mean (SD) latent intervals for VWF found in most of the surveys $\left(4(2)\right.$ years).$^{21}$ Nowadays, the observed reduction in the occurrence of VWF among forestry workers who use AV chain saws may suggest a revision of the risk estimates for VWF provided by ISO 5349. ${ }^{22}$

The aim of this study was to investigate the prevalence of VWF among forestry workers currently exposed to hand transmitted vibra- 
tion from AV chain saws. The diagnosis of VWF was based on subjective symptoms of finger blanching and the results of a cold provocation test. From the measurements of chain saw vibration and the estimation of saw operating time, both daily vibration exposure and a lifetime vibration dose were obtained for each forestry worker. Finally, the relation between vibration exposure and VWF was studied.

\section{Materials and methods}

SUBJECTS AND MEDICAL INVESTIGATION

The study population included all of the 222 currently active forestry workers who use chain saws in three forest districts of Tuscany (Italy). They were identified by consulting the workforce records of the company. From the employment registers 10 retired forestry workers were also traced and included in the study population. Two hundred shipyard workers engaged in manual activities and never exposed to hand transmitted vibration formed the control group. They were mechanics, electricians, and maintenance operators who mainly worked outdoors. The controls were randomly recruited from a population of shipyard workers who attended annual compulsory medical examinations. The personal, work, and medical history of each worker was taken by direct interview performed by occupational health physicians. Health and workplace assessment questionnaires were also used during the interview. ${ }^{24}$ Both the forestry workers exposed to vibration and the controls were questioned about cigarette smoking (packyears), alcohol consumption (g/day), metabolic, cardiovascular, and neurological disorders, previous musculoskeletal injuries, and use of medicines. Four forestry workers and five controls were found to be affected with ischaemic heart disease or occlusive arterial disease of the lower limbs, and two forestry workers had non-insulin dependent diabetes. These subjects, together with four forestry workers with a total saw operating time of $<400$ hours, were excluded from data analysis. Therefore, the final sample consisted of 222 forestry workers and 195 controls.

The diagnosis of VWF was based on the simultaneous presence of the following subjective symptoms and objective test results: (a) positive history of cold provoked episodes of well demarcated blanching in one or more fingers after excluding primary Raynaud's disease or other secondary forms of Raynaud's phenomenon; (b) first appearance of finger blanching after the start of occupational exposure to hand transmitted vibration and experience of VWF attacks during the last two years; (c) abnormal digital arterial response to cold provocation. These diagnostic criteria were adopted to avoid misclassification of disease that could lead to biased estimates of the risk for VWF among the forestry workers. Clinically, VWF was graded according to the stages of the Stockholm scale: stage VWF0 = no finger blanching attacks; stage VWF1 = occasional attacks affecting only the tips of one or more fingers; stage VWF2 = occasional attacks affecting distal and middle (rarely proximal) phalanges of one or more fingers; stage VWF3 = frequent attacks affecting all phalanges of most fingers. ${ }^{25}$ In the affected workers the severity of VWF was assessed according to the stage of the worst hand.

\section{FINGER SYSTOLIC PRESSURE AND COLD} PROVOCATION

The cold test was performed on both the forestry workers and the controls after a rest period of 30 minutes in a laboratory room with a mean (SD) ambient temperature of $22(0.5)^{\circ} \mathrm{C}$. Systolic blood pressure of the finger (FSP) was measured after cold provocation of a test finger, with the cooling technique suggested by Nielsen and Lassen. ${ }^{26} \mathrm{~A}$ double inlet plastic cuff for both air filling and water perfusion was placed on the middle phalanx of the third left finger. In the people with subjective symptoms of VWF, the most affected finger was cooled. The test finger was warmed and cooled with water circulating at $30^{\circ} \mathrm{C}$ and $10^{\circ} \mathrm{C}$ with a digit cooling system (Medimatic A/S, Copenhagen, Denmark). Two air filled cuffs were applied, one to the proximal phalanx of the test finger (for ischaemia during cooling) and one to the middle phalanx of a control finger of the same hand (usually the fourth finger). The cold test was performed by pressurising the air cuffs to a suprasystolic level $(210 \mathrm{~mm} \mathrm{Hg})$ and perfusing the water cuff with water initially at $30^{\circ} \mathrm{C}$ and then at $10^{\circ} \mathrm{C}$. After five minutes of ischaemic cooling, FSP was measured on the test and control fingers by strain gauge plethysmographic technique. Arm systolic pressure (ASP) was measured by a mercury sphygmomanometer with a standard cuff. The following pressure indices were derived from the arm and finger systolic pressures:

(1) The change of systolic blood pressure of the test finger at $10^{\circ} \mathrm{C}\left(\mathrm{FSP}_{\mathrm{t}, 10^{\circ}}\right)$ as a percentage of the pressure at $30^{\circ} \mathrm{C}\left(\mathrm{FSP}_{\mathrm{t}, 30^{\circ}}\right)$, corrected for the change of pressure in the control finger during the cold test $\left(\mathrm{FSP}_{\text {ref } 30^{\circ}}-\right.$ FSP $_{\text {ref, } 10^{\circ}}$ ):

$$
\begin{gathered}
\mathrm{FSP} \%_{10^{\circ}}=\left(\mathrm{FSP}_{\mathrm{t}, 10^{\circ}} \cdot 100\right) /\left(\mathrm{FSP}_{\mathrm{t}, 30^{\circ}}-\right. \\
\left(\mathrm{FSP}_{\mathrm{ref}, 30^{\circ}}-\mathrm{FSP}_{\mathrm{ref}, 10^{\circ}}\right)(\%)
\end{gathered}
$$

(2) The reduction in finger systolic pressure (R-FSP) by cooling the test finger from $30^{\circ}$ to $10^{\circ} \mathrm{C}$ :

$$
\begin{aligned}
& \text { R-FSP } 10^{\circ}=\left(\mathrm{FSP}_{\mathrm{t}, 30^{\circ}}-\mathrm{FSP}_{\mathrm{t}, 10^{\circ}}\right)-\left(\mathrm{FSP}_{\mathrm{ref}, 30^{\circ}}-\right. \\
& \text { FSP } \left._{\text {ref,10 }}\right)(\mathrm{mm} \mathrm{Hg})
\end{aligned}
$$

(3) The digital pressure index in the test finger at $30^{\circ}$ and $10^{\circ} \mathrm{C}\left(\mathrm{DPI}_{\mathrm{x}^{\circ}}\right)$, calculated as the ratio of FSP to ASP:

$$
\operatorname{DPI}_{\mathrm{x}^{\circ}}=\left(\mathrm{FSP}_{\mathrm{t}, \mathrm{x}^{\circ}} \cdot 100\right) / \operatorname{ASP}_{\mathrm{x}^{\circ}}(\%)
$$

To avoid nicotine induced vasoconstrictive effects on the digital arteries, tobacco users had stopped smoking for at least two hours before testing.

In the control subjects of this study, the lower limit of $\mathrm{FSP} \%_{10^{\circ}}$ (mean - 2SDs) was $72 \cdot 2 \%$. For epidemiological purposes, the finding of $\mathrm{FSP} \%_{10^{\circ}}<70 \%$ was considered to 
Table 1 Frequency weighted vibration acceleration magnitudes $\left(m \cdot s^{-2}\right)$ measured in three orthogonal directions $\left(a_{x, h, w}, a_{y, h, w}, a_{z, h, w}\right)$ at the front and rear handles of the antivibration ( $A V$ ) chain saws used by the forestry workers (the acceleration magnitudes measured on non- $A V$ chain saws used in the past are also reported

\begin{tabular}{|c|c|c|c|c|c|c|c|}
\hline \multirow[b]{2}{*}{ Saw type } & \multirow[b]{2}{*}{$n$} & \multicolumn{3}{|c|}{ Front handle } & \multicolumn{3}{|c|}{ Rear handle } \\
\hline & & $a_{x, h, w}$ & $a_{y, h, w}$ & $a_{z, h, w}$ & $a_{x, h, w}$ & $a_{y, h, w}$ & $a_{z, h, w}$ \\
\hline AV chain saws & 27 & $\begin{array}{l}3.92 \\
(1 \cdot 17)\end{array}$ & $\begin{array}{l}3 \cdot 73 \\
(1 \cdot 40)\end{array}$ & $\begin{array}{l}4 \cdot 40 \\
(1 \cdot 35)\end{array}$ & $\begin{array}{l}4 \cdot 18 \\
(1 \cdot 25)\end{array}$ & $\begin{array}{l}5 \cdot 95 \\
(1 \cdot 21)\end{array}$ & $\begin{array}{l}6 \cdot 35 \\
(1 \cdot 75)\end{array}$ \\
\hline $\begin{array}{l}\text { Non-AV chain } \\
\text { saws }\end{array}$ & 3 & $\begin{array}{l}9 \cdot 52 \\
(1 \cdot 85)\end{array}$ & $\begin{array}{l}8 \cdot 87 \\
(1 \cdot 64)\end{array}$ & $\begin{array}{l}10.5 \\
(1.81)\end{array}$ & $\begin{array}{l}14 \cdot 1 \\
(2 \cdot 01)\end{array}$ & $\begin{array}{l}10 \cdot 0 \\
(1 \cdot 76)\end{array}$ & $\begin{array}{l}15 \cdot 2 \\
(1.94)\end{array}$ \\
\hline
\end{tabular}

Values are mean (SD).

be an abnormal response to cold provocation in the digital arteries of the forestry workers with subjective symptoms of VWF.

\section{MEASUREMENT AND ASSESSMENT OF VIBRATION EXPOSURE}

Vibration was measured on the front and rear handles of $27 \mathrm{AV}$ chain saws used in the forest districts (mean (SD) weight $5.2(0.9) \mathrm{kg}$; bar length 43 (5) cm; displacement $54(10) \mathrm{cc}$, engine speed $8800(520) \mathrm{rpm})$. The sample included over $90 \%$ of the chain saw models handled by the forestry workers. To assess previous exposure to hand transmitted vibration in elderly forestry workers, vibration from three non-AV chain saws used in the past was also measured. Vibration measurements were made in the field during cross cutting operations performed by skilled workers according to the procedure suggested by ISO $7505 . .^{27}$ Three Brüel and Kjær (B\&K) miniature accelerometers (B\&K 4374) were attached to an adaptor (B\&K 0894) tightened around the saw handle by means of suitable clamps. A butyl rubber sheet (B\&K DS 0707) was interposed between the adaptor and the saw handle. Before vibration measurement, the accelerometers were calibrated (B\&K 4294) and the accelerometer connecting cables were taped to minimise errors from triboelectric effects. The accelerometer signals were amplified (B\&K 2635) and recorded on digital or FM tape recorders. The acceleration recordings were analysed in the laboratory by a digital frequency analyser. From the one third octave band frequency spectra $(6 \cdot 3-1250 \mathrm{~Hz})$, the root mean square ( $\mathrm{rms}$ ) of the frequency weighted acceleration was obtained after

Table 2 Characteristics of the forestry workers and the controls

\begin{tabular}{|c|c|c|}
\hline & $\begin{array}{l}\text { Controls } \\
(n=195)\end{array}$ & $\begin{array}{l}\text { Forestry workers } \\
(n=222)\end{array}$ \\
\hline $\begin{array}{l}\text { Age (y): } \\
\text { Cigarette smoking (pack-y): }\end{array}$ & $45 \cdot 1(10 \cdot 4)$ & $45 \cdot 3(11 \cdot 8)$ \\
\hline $\begin{array}{l}\quad 0 \\
<15 \\
\geqslant 15\end{array}$ & $\begin{array}{ll}68 & (34 \cdot 9) \\
51 & (26 \cdot 2) \\
76 & (39 \cdot 0)\end{array}$ & $\begin{array}{ll}66 & (29 \cdot 7) \\
65 & (29 \cdot 3) \\
91 & (41 \cdot 0)\end{array}$ \\
\hline $\begin{array}{l}\text { Alcohol }(\mathrm{g} / \text { day }) \text { : } \\
\quad 06 \\
\quad<60 \\
\geqslant 60 \\
\text { Duration of exposure }(y) \\
\text { Yearly exposure }(\mathrm{h} / \mathrm{y}) \\
\text { A }(8) \dagger\left(\mathrm{m} \cdot \mathrm{s}^{-2}\right) \\
\mathrm{Lifetime} \text { vibration dose } \neq \\
\left(\ln \left(\mathrm{m}^{2} \mathrm{~s}^{-4} \mathrm{hd}\right)\right)\end{array}$ & $\begin{aligned} 36 & (18 \cdot 5) \\
108 & (55 \cdot 4) \\
51 & (26 \cdot 2) \\
- & \\
- & \\
- & \end{aligned}$ & $\begin{array}{cl}32 & (14 \cdot 4) \\
82 & (36 \cdot 9) \\
108 & (48 \cdot 6)^{\star} \\
11 \cdot 1 & (7 \cdot 6) \\
714 \quad(387) \\
4.39 & (0 \cdot 94) \\
19.8 & (1.9)\end{array}$ \\
\hline
\end{tabular}

$\star P<0.001$ with $\chi^{2}$ test.

$\dagger A(8)$ is the frequency weighted energy equivalent acceleration for a period of $8 h$.

Lifetime vibration dose is expressed on a logarithmic (ln) scale.

Values are mean (SD) or $\mathrm{n}(\%)$. applying the weighting factors recommended by ISO 5349..$^{22}$ Table 1 reports the results of vibration measurements from the front and rear handles of both $\mathrm{AV}$ and non-AV chain saws. On average, the magnitude of frequency weighted acceleration from the AV chain saws varied from $3.73 \mathrm{~m} \cdot \mathrm{s}^{-2}$ (front handle) to $6.35 \mathrm{~m} \cdot \mathrm{s}^{-2}$ (rear handle). The mean value of the frequency weighted, dominant, single axis component of vibration from non-AV chain saws was greater than that measured on AV saws, which ranged between 10.5 and $15 \cdot 2 \mathrm{~m} \cdot \mathrm{s}^{-2}$.

The forestry workers were asked to give a detailed list of the types of chain saw used during their professional career. To assess saw operating time ( $\mathrm{h} / \mathrm{day}$, days/y, and total years) several information sources were used: workplace assessment questionnaires validated by direct interviews with employers and employees, employment records, and amount of fuel used by the chain saws. Daily duration of saw use was found to vary widely among the forestry workers, from two to five hours according to their specific tasks within the work organisation of the group. The oldest forestry workers reported duration of saw use up to seven hours/day in the past. Daily exposure to saw vibration was assessed in terms of eight hour energy equivalent frequency weighted acceleration (A(8) in $\mathrm{m} \cdot \mathrm{s}^{-2}$ ) according to the British standard 6842:

$$
A(8)=\left(\frac{1}{T_{8}} \int_{0}^{T}\left(a_{\mathrm{h}, \mathrm{w}}(t)\right)^{2} d t\right)^{\frac{1}{2}}\left(\mathrm{~m} \cdot \mathrm{s}^{-2}\right)
$$

where $T 8$ is the duration of eight hours, $\mathrm{T}$ is the total duration of the working day in hours, and $a_{\mathrm{h}, \mathrm{w}}(t)$ is the instantaneous value of the frequency weighted acceleration in $\mathrm{m} \cdot \mathrm{s}^{-2} .^{28}$

On the basis of the estimated periods of saw use, a lifetime vibration dose for each forestry worker was calculated by a method of summation suggested by Griffin:

$$
\begin{gathered}
\text { Lifetime dose }= \\
\left(\sum\left(a_{h, w}{ }^{2} \cdot t_{h}\right)^{\frac{1}{2}} \cdot t_{d} \cdot t_{y}\right)^{2}\left(m^{2} s^{-4} h d\right)
\end{gathered}
$$

where $a_{h, w}$ is the frequency weighted acceleration measured on the chain saws $\left(\mathrm{m} \cdot \mathrm{s}^{-2}\right), \mathrm{t}_{\mathrm{h}}$ is the individually estimated daily exposure ( $h /$ day), $t_{d}$ is the number of working days/y, and $t_{y}$ is the number of years of saw use. ${ }^{29}$

\section{STATISTICAL METHODS}

Data analysis was performed by the BMDP/ Dynamic software (Release 7·0). Continuous data was summarised with mean or median as measures of central tendency and SD or lower and upper quartiles as measures of dispersion. The difference between independent groups was tested by the Kruskal-Wallis one way analysis of variance and multiple comparisons. The difference between categorical data tabulated in $2 \times k$ contingency tables was tested by the $\chi^{2}$ statistic. Unconditional logistic regression analysis was used to assess the association between vibration exposure and VWF. Prevalence odds ratios (ORs), adjusted for several covariates, were obtained by taking the antilog of the estimates of the logistic regres- 
Table 3 Distribution of symptoms of vibration induced white finger (VWF) by stages among the forestry workers, divided into subjects with work experience with nonantivibration (non- $A V$ ) as well as $A V$ saws, and subjects with experience limited to $A V$ saws only (Raynaud's symptoms among the controls are also reported).

\begin{tabular}{|c|c|c|c|c|}
\hline \multirow[b]{2}{*}{ Stages of $V W F^{\star}$} & \multirow[b]{2}{*}{$\begin{array}{l}\text { Controls } \\
(n=195) \\
(n(\%))\end{array}$} & \multicolumn{3}{|l|}{ Forestry workers } \\
\hline & & $\begin{array}{l}A V \text { saws } \\
(n=164) \\
(n(\%))\end{array}$ & $\begin{array}{l}\text { Non }-A V \text { and } \\
A V \text { saws } \\
(n=58) \\
(n(\%))\end{array}$ & $\begin{array}{l}\text { Total } \\
(n=222) \\
(n(\%))\end{array}$ \\
\hline $\begin{array}{l}\text { VWF0 } \\
\text { VWF1 } \\
\text { VWF2 } \\
\text { VWF3 } \\
\text { VWF1 + 2+3 }\end{array}$ & $\begin{array}{c}189(96 \cdot 9) \\
4(2 \cdot 1) \\
1(0 \cdot 5) \\
0(0) \\
5(2 \cdot 6)\end{array}$ & $\begin{array}{c}142(86 \cdot 6) \\
8(4 \cdot 9) \\
7(4 \cdot 3) \\
7(4 \cdot 3) \\
22(13 \cdot 4)\end{array}$ & $\begin{array}{c}28(48 \cdot 3) \\
3(5 \cdot 2) \\
17(29 \cdot 3) \\
10(17 \cdot 2) \\
30(51 \cdot 7)\end{array}$ & $\begin{array}{c}170(76 \cdot 6) \\
11(5 \cdot 0) \\
24(10 \cdot 8) \\
17(7 \cdot 7) \\
52(23 \cdot 4)\end{array}$ \\
\hline OR $(95 \%$ CI $)$ & $1 \cdot 0(-)$ & $6 \cdot 21(2 \cdot 26-17 \cdot 1)$ & $32 \cdot 3(11 \cdot 2-93 \cdot 3)$ & $11 \cdot 8(4 \cdot 47-31 \cdot 1)$ \\
\hline
\end{tabular}

^Raynaud's symptoms in the controls.

ORs (95\% CIs) for VWF (stages $1+2+3$ ) among forestry workers $v$ controls were adjusted for age, smoking, and drinking habits by logistic modelling.

Table 4 Dose-response relation for vibration induced white finger among the forestry workers, divided into categories of lifetime vibration dose (ln scale)

\begin{tabular}{|c|c|c|c|c|}
\hline & \multicolumn{4}{|c|}{ Lifetime vibration dose $\left(\ln \left(m^{2} s^{-4} h d\right)\right)$} \\
\hline & $\begin{array}{l}<19 \\
(n=54)\end{array}$ & $\begin{array}{l}19-20 \\
(n=56)\end{array}$ & $\begin{array}{l}20-21 \\
(n=56)\end{array}$ & $\begin{array}{l}>21 \\
(n=56)\end{array}$ \\
\hline $\begin{array}{l}\text { No }(\%) \\
\text { OR }(95 \% \mathrm{CI})^{\star} \\
\text { IOR }(95 \% \mathrm{CI})^{\star \star}\end{array}$ & $\begin{array}{l}4(7 \cdot 4) \\
4.06(1.06-16 \cdot 4)\end{array}$ & $\begin{array}{l}6(10 \cdot 7) \\
4 \cdot 65(1 \cdot 34-16 \cdot 1) \\
1 \cdot 12(0 \cdot 36-3 \cdot 52)\end{array}$ & $\begin{array}{l}12(21 \cdot 4) \\
9 \cdot 37(3 \cdot 10-28 \cdot 4) \\
1 \cdot 81(1 \cdot 38-2 \cdot 37)\end{array}$ & $\begin{array}{l}30(53 \cdot 6) \\
34 \cdot 3(11 \cdot 9-99 \cdot 2) \\
4 \cdot 12(2 \cdot 01-8 \cdot 44)\end{array}$ \\
\hline
\end{tabular}

${ }^{\star} \chi^{2}=3.46, \mathrm{P}=0.902 ;{ }^{\star \star} \chi^{2}=2.32, \mathrm{P}=0.970$ : Goodness of fit of the logistic model (HosmerLemeshow statistic)

ORs ( $95 \%$ CIs) adjusted for age, smoking and drinking habits, were obtained by logistic regression $v$ controls (OR 1.0). IOR contrasts the risk at each category of vibration exposure with the risk at only the next lower category, omitting the controls from the dose-response analysis.

sion coefficients $\left(\exp \left(b_{i}\right)\right)$. Ninety five per cent confidence intervals ( $95 \% \mathrm{CIs}$ ) were calculated with the estimated coefficients and the SEMs from the logistic regression. Both exposure variables and confounding factors entered the logistic model as categorical covariates, except for age, which was used as a continuous covariate. The significance of additional variables in the logistic model was tested by the likelihood ratio statistic. The goodness of fit of the logistic model was assessed by the Hosmer-Lemeshow $\chi^{2}$ statistic. $^{30}$ To evaluate the hypothesis that among the forestry workers the risk of VWF continued to increase with further increases in vibration exposure, logistic regression analysis was used. A logistic regression model was fitted that included a linear term for age and a quadratic term for log dose. The results were summarised by dividing the exposure into ranges and quoting the fitted values as incremental odds ratios (IORs). The IORs contrast the risk for VWF at each exposure category with the risk at the level immediately below it. ${ }^{31}$ The controls were excluded from the quantitative dose-response analysis.

\section{Results}

VASCULAR DISORDERS INDUCED BY VIBRATION The chain saw operators and the controls were comparable for age and smoking habit (table 2). Alcohol consumption was stronger in the forestry workers than in the controls $(P<$ 0.001 ). In the forestry worker group, the number of years of saw use and the total operating time averaged $11 \cdot 1$ years and 8000 hours, respectively. The mean value of daily vibration exposure estimated in terms of $\mathrm{A}(8)$ was 4.39 (SD 0.94$) \mathrm{m} \cdot \mathrm{s}^{-2}$. Among the forestry workers, 164 subjects $(73.9 \%)$ had work experience limited to AV chain saws only, whereas 58 subjects $(26 \cdot 1 \%)$ had operated both non-AV and AV chain saws. Five controls $(2 \cdot 6 \%)$ reported Raynaud like symptoms at the medical interview (table 3 ). The overall prevalence of VWF among the forestry workers was found to be $23.4 \%$ (OR $11 \cdot 8$ ). Within the forestry worker group the diagnosis of VWF was made in $13.4 \%$ of the subjects who handled only AV chain saws and in $51.7 \%$ of the subjects who had also operated chain saws without vibration isolation systems. Compared with controls, the adjusted OR for white finger was significantly higher for both the forestry workers with exposure limited to AV saws (OR 6.21) and the forestry workers with non-AV and AV sawing experience (OR 32.3, $\mathrm{P}<0.0001$ ). After allowing for age, duration of exposure, smoking and drinking habits, the OR for VWF for the operators of non-AV and AV saws $v$ operators of AV saws only was 4.00 (95\% CI $1 \cdot 08-14 \cdot 7, P=0 \cdot 026)$. Moreover, moderate and severe VWF (stages 2 and 3) were found more frequently among the forestry workers with past experience of non-AV chain saws $(\mathrm{P}<0.01)$.

When the forestry workers were divided into several categories of lifetime vibration dose, significant associations were found between the prevalence of VWF and vibration exposure (table 4). The prevalence of VWF was found to increase with increasing lifetime

Table 5 Finger systolic pressure (FSP) during local cooling from $30^{\circ} \mathrm{C}$ to $10^{\circ} \mathrm{C}$ in the controls and the forestry workers divided into several categories of lifetime vibration dose (ln scale)

\begin{tabular}{|c|c|c|c|c|c|}
\hline & \multirow[b]{2}{*}{$\begin{array}{l}\text { Controls } \\
(n=195)\end{array}$} & \multicolumn{4}{|c|}{ Forestry workers (lifetime vibration dose $\left(\ln \left(m^{2} s^{-4} h d\right)\right)$} \\
\hline & & $\begin{array}{l}<19 \\
(n=54)\end{array}$ & $\begin{array}{l}19-20 \\
(n=56)\end{array}$ & $\begin{array}{l}20-21 \\
(n=56)\end{array}$ & $\begin{array}{l}>21 \\
(n=56)\end{array}$ \\
\hline $\mathrm{FSP}_{\mathrm{t}, 30^{\circ}}(\mathrm{mm} \mathrm{Hg})$ & $124(110-140)$ & $126(122-139)$ & $130(121-145)$ & $132(119-142)$ & $125(114-142)$ \\
\hline $\mathrm{DPI}_{30^{\circ}}(\%)$ & $93 \cdot 9(85 \cdot 7-99 \cdot 2)$ & $95 \cdot 6(83 \cdot 2-100)$ & $93 \cdot 4(84 \cdot 6-105)$ & $93 \cdot 7(85 \cdot 8-102)$ & $88 \cdot 8(78 \cdot 8-95 \cdot 6)$ \\
\hline FSP $\%_{10^{\circ}}(\%)$ & $100(90 \cdot 7-100)$ & $90 \cdot 2(76 \cdot 4-100)$ & $83 \cdot 7(71 \cdot 4-95 \cdot 7)$ & $77 \cdot 8(59 \cdot 9-89 \cdot 6)$ & $61 \cdot 2(36 \cdot 8-85 \cdot 3)^{\star}$ \\
\hline $\mathrm{R}^{-F} \mathrm{P}_{10^{\circ}}(\mathrm{mm} \mathrm{Hg})$ & $0(0-12 \cdot 0)$ & $11 \cdot 5(0-32 \cdot 5)$ & $21 \cdot 5(5 \cdot 3-36 \cdot 3)$ & $29 \cdot 0(13 \cdot 8-57 \cdot 3)$ & $50 \cdot 0(18 \cdot 5-83 \cdot 0)^{\star}$ \\
\hline $\operatorname{DPI}_{10^{\circ}}(\%)$ & $90 \cdot 0(81 \cdot 3-103)$ & $83 \cdot 3(67 \cdot 2-95 \cdot 5)$ & $82 \cdot 8(67 \cdot 6-94 \cdot 0)$ & $74 \cdot 7(54 \cdot 9-90 \cdot 4)$ & $51 \cdot 7(29 \cdot 8-79 \cdot 2)^{\star}$ \\
\hline
\end{tabular}

${ }^{\star} \mathrm{P}<0.0001 \mathrm{Kruskal}-\mathrm{Wallis}$ test. $\mathrm{FSP} \%_{10^{\circ}}=$ the finger systolic pressure in the test finger cooled to $10^{\circ} \mathrm{C}$ as a percentage of pressure at $30^{\circ} \mathrm{C}\left(\mathrm{FSP}_{t, 30^{\circ}}\right)$; R-FSP ${ }_{10^{\circ}}=$ the reduction in finger systolic pressure from $30^{\circ} \mathrm{C}$ to $10^{\circ} \mathrm{C}$; DPI is the digital pressure index at $30^{\circ} \mathrm{C}$ and $10^{\circ} \mathrm{C}$; ; values are medians (lower and upper quartiles). 
Table 6 Results of the cold provocation test in the forestry workers affected by vibration induced white finger (VWF), classified according to the Stockholm stages

\begin{tabular}{|c|c|c|c|}
\hline & \multicolumn{3}{|l|}{ Stages of VWF } \\
\hline & $\begin{array}{l}V W F 1 \\
(n=11)\end{array}$ & $\begin{array}{l}V W F 2 \\
(n=24)\end{array}$ & $\begin{array}{l}V W F 3 \\
(n=17)\end{array}$ \\
\hline $\mathrm{FSP}_{\mathrm{t}, 30^{\circ}}(\mathrm{mm} \mathrm{Hg})$ & $118(98-136)$ & $127(114-142)$ & $122(102-139)$ \\
\hline $\mathrm{DPI}_{30^{\circ}}(\%)$ & $81 \cdot 7(75 \cdot 4-97 \cdot 9)$ & $88 \cdot 3(80 \cdot 5-98 \cdot 4)$ & $91 \cdot 2(70 \cdot 2-97 \cdot 6)$ \\
\hline $\mathrm{FSP}_{10^{\circ}}(\%)$ & $47 \cdot 0(31 \cdot 0-55 \cdot 0)$ & $45 \cdot 1(29 \cdot 8-54 \cdot 0)$ & $30 \cdot 8(0-47 \cdot 8)^{\star}$ \\
\hline R-FSP ${ }_{10^{\circ}}(\mathrm{mm} \mathrm{Hg})$ & $70 \cdot 0(45 \cdot 0-92 \cdot 0)$ & $74 \cdot 0(52 \cdot 0-88 \cdot 5)$ & $83.9(64.0-108)^{\star}$ \\
\hline $\operatorname{DPI}_{10^{\circ}}(\%)$ & $37 \cdot 6(26 \cdot 9-55 \cdot 2)$ & $40 \cdot 0(25 \cdot 9-54 \cdot 5)$ & $27 \cdot 0(0-43.5)^{\star \star}$ \\
\hline
\end{tabular}

${ }^{\star} P=0.04 ;{ }^{\star \star} P<0.03$ Kruskal-Wallis test. Abbreviations are as for table 5; values are medians (lower and upper quartiles).

vibration dose, and after adjustment for potential confounders the OR for VWF was significantly greater than unity for each category of vibration dose when compared with the controls. Furthermore, within the forestry worker group the adjusted estimates of IOR indicated that the risk for VWF continuously increased with increasing vibration dose. It is worth noting that the highest incremental risk of VWF was found for the greatest dose category, which included most of the subjects with past exposure to vibration from non-AV chain saws.

\section{DIGITAL ARTERIAL COLD RESPONSE AND} VIBRATION EXPOSURE

Table 5 shows the results of the cold provocation test in the controls and the forestry workers by vibration exposure. In basal conditions with the water cuff at $30^{\circ} \mathrm{C}$, no differences among the various groups were found for FSP and DPI measured in the test finger. Finger cooling to $10^{\circ} \mathrm{C}$ provoked a stronger reduction in FSP among the forestry workers than among the controls. Between the controls and the forestry workers divided into categories of vibration dose, the change in the digital pressure indices $\left(\mathrm{FSP} \%_{10^{\circ}}, \mathrm{R}-\mathrm{FSP}_{10^{\circ}}\right.$, and $\left.\mathrm{DPI}_{10^{\circ}}\right)$ differed significantly $(P<0 \cdot 0001)$. A multiple comparison test showed that the forestry workers who had accumulated more than $21 \mathrm{~m}^{2} \mathrm{~s}^{-4}$ hd (ln scale) had a significantly increased cold response compared with those with a lower vibration dose $(P<0.01)$. In the VWF group, the chain saw operators who reported severe white finger symptoms (stage 3) showed a more intense digital vasospasm during local cooling to $10^{\circ} \mathrm{C}$ than those with

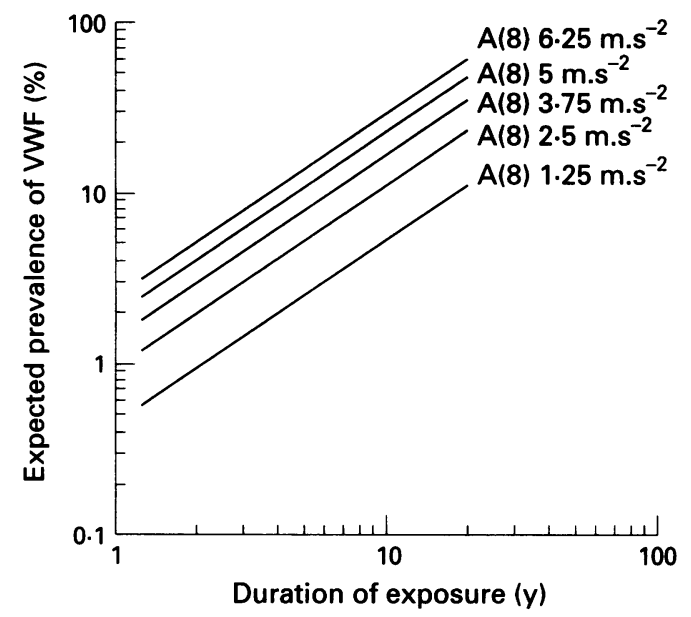

Expected prevalence of vibration induced white finger (VWF\%) among the forestry workers as a function of eight hour frequency weighted energy equivalent acceleration $\left(A(8)\right.$ in $\left.\mathrm{m}^{-\mathrm{s}^{-2}}\right)$ and the total duration of vibration exposure $(D, y)$ :

$V W F=0.35381 \cdot(A(8))^{1.053} \cdot\left(D_{y}\right)^{1.073}(\%)$

mild or moderate symptoms of finger blanching attacks (stages 1 and 2, table 6). Among the forestry workers without VWF, both those operating AV saws only $(n=142)$ and those with non-AV and AV sawing experience (n = 28) showed lower values of FSP $\%_{10^{\circ}}(84 \%$ and $77 \%$, respectively) than the controls ( $P<$ $0.001)$.

EXPOSURE-RESPONSE RELATION FOR VWF

For the purposes of comparison with the exposure-response guidances given by some standards, ${ }^{22} 28$ the estimated prevalence of VWF was regressed on the midpoints of several intervals of daily vibration exposure $(A(8)$ in $\left.\mathrm{m} \cdot \mathrm{s}^{-2}\right)$ and total duration of exposure $\left(D_{y}\right.$ in years). Even though several models that involved transformations of the response or the explanatory variables (arc-sine or power transformations) were found to fit equally well, ${ }^{32}$ a $\log \log$ model was finally used to make the results comparable with those reported in annex $\mathrm{A}$ to the standard ISO 5349. ${ }^{22}$ The form of the relation between the prevalence of VWF and vibration exposure could be adequately modelled by the following equation:

$$
\mathrm{VWF}=0.35381 \cdot(\mathrm{A}(8))^{1.053} \cdot\left(\mathrm{D}_{\mathrm{y}}\right)^{1.073}(\%)
$$

The figure gives a graphical presentation of the results of the regression analysis. For the expo-

Table 7 Frequency weighted vibration acceleration magnitudes $\left(m \cdot \mathrm{s}^{-2} \mathrm{rms}\right)$ that may be expected to produce finger blanching in $10 \%$ of the forestry workers (for comparison, the corresponding acceleration magnitudes provided by the British standard 6842 are included in parentheses: see figure legend for the estimated regression equation)

\begin{tabular}{|c|c|c|c|c|c|c|}
\hline \multirow{2}{*}{$\begin{array}{l}\text { Daily } \\
\text { exposure }\end{array}$} & \multicolumn{6}{|c|}{ Lifetime exposure } \\
\hline & 6 months & $1 y$ & $2 y$ & $4 y$ & $8 y$ & $16 y$ \\
\hline $8 \mathrm{~h}$ & $\begin{array}{l}48 \cdot 4 \\
(44 \cdot 8)\end{array}$ & $\begin{array}{l}23 \cdot 9 \\
(22 \cdot 4)\end{array}$ & $11 \cdot 8$ & $5 \cdot 8$ & 2.9 & 1.4 \\
\hline $4 \mathrm{~h}$ & 68.5 & $33 \cdot 8$ & $16 \cdot 7$ & $\begin{array}{l}(3 \cdot 0) \\
8 \cdot 2\end{array}$ & $\begin{array}{l}(2 \cdot 8) \\
4 \cdot 1\end{array}$ & $\begin{array}{l}(1 \cdot 4) \\
2 \cdot 0\end{array}$ \\
\hline $2 \mathrm{~h}$ & $96 \cdot 8$ & $47 \cdot 8$ & $\begin{array}{l}(10.0) \\
23.6\end{array}$ & $\begin{array}{l}(8.0) \\
11.6\end{array}$ & $\begin{array}{l}(4 \cdot 0) \\
5 \cdot 7\end{array}$ & $\begin{array}{l}(2 \cdot 0) \\
2 \cdot 8\end{array}$ \\
\hline $1 \mathrm{~h}$ & $\begin{array}{l}(89.0) \\
136.9\end{array}$ & $\begin{array}{l}(44.8) \\
67 \cdot 6\end{array}$ & $\begin{array}{l}(22 \cdot 4) \\
33 \cdot 3\end{array}$ & $\begin{array}{l}(11 \cdot 2) \\
16 \cdot 5\end{array}$ & $\begin{array}{l}(5 \cdot 6) \\
8 \cdot 1\end{array}$ & $\begin{array}{l}(2 \cdot 8) \\
4 \cdot 0\end{array}$ \\
\hline $30 \mathrm{~min}$ & $\begin{array}{l}(128.0) \\
193.6\end{array}$ & $\begin{array}{l}(64.0) \\
95 \cdot 6\end{array}$ & $\begin{array}{l}(32 \cdot 0) \\
47 \cdot 2\end{array}$ & $\begin{array}{l}(16 \cdot 0) \\
23 \cdot 3\end{array}$ & $\begin{array}{l}(8 \cdot 0) \\
11 \cdot 6\end{array}$ & $\begin{array}{l}(4 \cdot 0) \\
5 \cdot 7\end{array}$ \\
\hline $15 \mathrm{~min}$ & $\begin{array}{l}(179 \cdot 2) \\
273 \cdot 9 \\
(256 \cdot 0)\end{array}$ & $\begin{array}{l}(89 \cdot 6) \\
135 \cdot 1 \\
(128 \cdot 0)\end{array}$ & $\begin{array}{l}(44 \cdot 8) \\
66 \cdot 7 \\
(64 \cdot 0)\end{array}$ & $\begin{array}{l}(22 \cdot 4) \\
32 \cdot 9 \\
(32 \cdot 0)\end{array}$ & $\begin{array}{l}(11 \cdot 2) \\
16 \cdot 2 \\
(16 \cdot 0)\end{array}$ & $\begin{array}{l}(5 \cdot 6) \\
8 \cdot 0 \\
(8 \cdot 0)\end{array}$ \\
\hline
\end{tabular}


sure conditions of the chain saw operators of this study, the fitted model indicates that the expected percentage of workers affected with VWF will vary roughly linearly with either $A(8)$ (with $D_{y}$ unchanged) or total exposure duration (with equivalent acceleration unchanged). The regression model was also used to estimate the frequency weighted acceleration magnitudes $\left(a_{h, w}\right)$ that may be expected to cause VWF in selected percentiles of workers exposed to vibration. Table 7 reports the rms values of $a_{h, w}$ for a $10 \%$ prevalence of finger blanching symptoms according to the British standard 6842. ${ }^{28}$ Except for extremely low daily and lifetime exposures, there is evidence for an excellent agreement between the vibration acceleration magnitudes estimated by our regression model and those provided by the British standard.

\section{Discussion}

The findings of this study are consistent with previous reports of a lower prevalence of VWF among forestry workers exposed to vibration from AV chain saws than those exposed to both non-AV and AV saws. ${ }^{12-15}$ It seems that the use of AV chain saws may induce vascular disorders in the fingers of the exposed workers as VWF was diagnosed in $13.4 \%$ of the forestry workers with sawing experience limited to AV saws. Similar findings have also been reported by other investigators. In a prospective study of chain saw operators nine years after the introduction of anti-vibration measures, Riddle and Taylor found VWF symptoms in $17 \%$ of active sawyers who had only operated AV chain saws. ${ }^{14}$ In a recent Japanese study, Mirbod et al found symptoms and signs of VWF in $9.6 \%$ of 447 private forestry workers exposed to AV saw vibration with an acceleration of $2 \cdot 7-5 \cdot 1 \mathrm{~m} \cdot \mathrm{s}^{-2} \cdot{ }^{33} \mathrm{In}$ Canada, Brubaker et al reported a $28 \%$ increase in the occurrence of VWF in a group of forestry workers who had used only large AV saws (weighted acceleration: $4 \cdot 0-12 \cdot 4$ $\mathrm{m} \cdot \mathrm{s}^{-2}$ ) during a five year interval. ${ }^{34}$ These findings suggest that health surveillance should be maintained for saw operators who handle modern chain saws as the risk of developing VWF is still present in forest work.

Some epidemiological studies have shown that the prevalence of VWF tends to remain high among forestry workers who currently use AV chain saws and had been exposed to non-AV saw vibration in the past. In this study, the prevalence of VWF was $51.7 \%$ in this category of forestry workers. This figure is slightly greater than those reported in other surveys (43-49\%). ${ }^{14} 3435$ This may be due, at least partially, to the fact that AV chain saws were introduced later in Italy (after 1975-8) than in other countries.

In this study, the diagnosis of VWF was established on the basis of a positive history of finger blanching attacks confirmed by an abnormal digital arterial cold response. A monotonically increasing dose-response relation could be shown in the forestry workers as the risk for VWF showed positive increments with each increment of vibration dose. Some investigators have used indirect measures of vibration dose and simple statistics to test the association between VWF and vibration exposure. For instance, in a group of 266 Japanese chain saw operators Miyashita et al found a significant bivariate correlation between the occurrence of VWF and total hours of vibration exposure. ${ }^{36}$ Even though the definition of incremental risk as used in this study may seem to be very strict, it enables better evaluation of the dose-response relation than the usual correlation methods and tests for overall trend. ${ }^{31}$

In the present investigation, the responsiveness to cold in the digital arteries of the forestry workers was found to increase with increasing vibration dose and severity of VWF. This finding indicates that pathophysiological changes in the digital circulation were closely related to both exposure and clinical findings. An exaggerated digital arterial response to cold at $10^{\circ} \mathrm{C}$ was also noted in the operators without VWF who only used AV saws. This finding is consistent with previous cross sectional and longitudinal studies of forestry workers that pointed out that AV saw vibration can induce impairment to the vasoconstriction mechanisms even in chain saw operators without subjective white finger symptoms (preclinical Raynaud's symptoms). ${ }^{37} 38$ This gives additional support to the recommendation that forestry workers who use AV chain saws should be periodically monitored to detect early manifestations of VWF.

It is recognised that several sources of bias can affect cross sectional studies-such as, selection bias and information bias. In this study, all of the active forestry workers participated in the investigation so that self selection was avoided. To reduce selection bias, former chain sawyers, who had belonged to the group, were traced and included in the study population. Bias due to migration of workers affected with VWF to other jobs could not be estimated. According to the registers of the local department of the National Institute for Insurance of Occupational Accidents, no claims for VWF were made by retired or migrated chain saw operators who had worked in the surveyed forest districts. This does not mean that such workers were symptom free, nevertheless from a survey of the available literature it was considered that the occurrence of VWF in the study group was not severely underestimated. Exposure data were carefully checked in this study by several methods of investigation. Furthermore, vibration from non-AV chain saws previously used in the forest districts was measured to estimate cumulative vibration dose for men with long term saw vibration exposure. The main advantages of this study were that data on health conditions and several confounding factors were collected by direct interview of the workers, and their subjective finger symptoms were verified objectively by assessing the digital arterial response to a standardised, internationally accepted, cold provocation test.

In this study, the overall prevalence of VWF 
was $23.4 \%$ and the latent interval for VWF among the affected forestry workers averaged $9 \cdot 8$ (range 1-20) years. These figures are close to those reported in recent surveys of forestry workers exposed to AV saw vibration. ${ }^{33}{ }^{35}$ In general, the results of epidemiological studies show a pattern of lower prevalence of VWF associated with longer mean latency in forestry worker groups who use AV chain saws compared with those exposed in the past to a high magnitude of vibration from non-AV chain saws. ${ }^{21}{ }^{39}$ In addition to the damping of chain saw vibration, several other factors are likely to have improved the health of forestry workers, such as the lighter weight of the modern chain saws, the reduction in daily vibration exposure, and some changes in the organisation of forest work. ${ }^{1315}$

Annex A to ISO $5349^{22}$ proposes a doseresponse relation for VWF that can be approximated by the following equation:

$$
\mathrm{L}_{\mathrm{t}}=\left(9.5 \times \mathrm{C}^{\frac{1}{2}}\right) / \mathrm{A}(4)
$$

where $\mathrm{L}_{\mathrm{t}}$ is the exposure time before VWF (latency), $\mathrm{C}$ is the percentage of workers affected with VWF (prevalence), and $\mathrm{A}(4)$ is the energy equivalent frequency weighted acceleration for a period of four hours - that is, $A(4)=A(8) \cdot \sqrt{2}$. On the basis of the observed prevalence of VWF and the estimated $A(4)$ for the forestry workers of this study, the ISO equation predicts that the latent interval for VWF should average 7.4 years. In terms of prevalence of VWF, $41 \%$ of the forestry workers should be expected to show vascular disorders according to the ISO equation. These figures indicate an overestimation of the risk for VWF compared with the observed data. Several reports have shown that the ISO equation tends to predict an excessive risk of VWF among worker groups who use percussive vibrating tools generating high magnitudes of vibration in the low frequency range. ${ }^{40-43}$ This tendency to overestimate the risk of VWF by ISO 5349 has also been found for chain saw operators. In a longitudinal study of 1330 Japanese state forestry workers, Futatsuka and Ueno found that the greater the saw vibration was, the larger the difference in the latencies for VWF from that predicted by the ISO standard. ${ }^{12}$ An overestimation of VWF prevalence was also found in our previous survey of forestry workers, $29 \cdot 2 \%$ of whom were affected with VWF $v 50.8 \%$ expected by the standard. ${ }^{44}$ As argued by the Japanese authors, one explanation for the discrepancy with ISO 5349 could be the heterogeneous exposure of those forestry workers who had operated nonAV chain saws and continued sawing with AV tools. ${ }^{12}$ Other investigators have pointed out that the uncertainty of the ISO prediction might derive from the use of the latent interval for VWF as a measure of effect. ${ }^{3944} 45$ Our clinical practice as occupational health physicians has shown that the latency time may be strongly subject to recall bias by the affected workers. Furthermore, the mean latency takes into account only the exposure duration of the subjects who have VWF, neglecting the overall vibration exposure accumulated by the worker group from which the cases of VWF arise. ${ }^{39}$ In this study, we used the prevalence of VWF as a measure of response. Potential sources of bias were carefully considered as it is known that prevalence is dependent on the rate at which the workforce changes. Despite this inherent limitation of cross sectional studies, it was decided that the prevalence of VWF, estimated on the basis of a dichotomous variable (presence or absence of finger blanching symptoms substantiated by the results of a cold test), could be a more reliable indicator of the effect induced by vibration than a subjective, very rough, continuous variable such as the latency for VWF.

In this study, vibration exposure was assessed according to the frequency weighting and the second power (energy) time dependency procedure included in current standards. ${ }^{22} 28$ It should be recognised that the frequency weighting curve of these standards is derived from experiments on the subjective and biodynamic responses of the hand arm system to vibration rather than from studies of chronic dysfunction induced by vibration in the digital vessels. Moreover, there are insufficient experimental and epidemiological data relating the energy time dependency to the adverse effects of hand transmitted vibration. Nevertheless, at the present state of knowledge the use of a frequency weighting based on the overall frequency dependence of the hand arm system seems to be acceptable. It has been pointed out that the energy time dependency represents a reasonable method for assessing at the workplace complex vibration exposures of different magnitudes and durations. ${ }^{28}$ It should be also considered that this time dependency is currently convenient to measure.

In this study of forestry workers, the expected prevalence of VWF was found to be a function of both daily vibration exposure and lifetime exposure periods. The estimated doseresponse relation between vibration exposure and VWF showed that if the daily vibration exposure, $A(8)$, is doubled, the total exposure duration (number of years) should be halved to produce an equivalent effect. This time dependency for cumulative vibration exposure conforms to that suggested by the British standard $6842 .{ }^{28}$ Our findings are also consistent with ISO predictions for low prevalence of VWF (around 10\%). For higher prevalences of VWF, the magnitude of vibration exposure estimated by the dose-response relation of this study tends to diverge from that predicted by ISO 5349-for example, for a daily eight hour continuous exposure at $4 \mathrm{~m} \cdot \mathrm{s}^{-2}$, ISO predicts a $30 \%$ prevalence of vascular symptoms after $9 \cdot 2$ years of regular vibration exposure $v 16 \cdot 1$ years suggested by this study. This may be due to several reasons, such as the use of different indices of exposure duration (the mean latency for the VWF workers in ISO 5349, the lifetime exposure for the entire worker group in this study), and the more severe vibration exposure of the various occupational groups selected to formulate the ISO dose-response relation (weighted accelerations between 12 and 28 
Table 8 Duration of exposure (y) for the onset of vibration induced white finger (VWF) in various percentages of forestry workers according to the vibration exposure levels of the directive for physical agents proposed by the Commission of the European Union (EUC): daily exposure to hand transmitted vibration is expressed in terms of $8 \mathrm{~h}$ frequency weighted energy equivalent acceleration ( $A(8)$; see figure legend for the estimated regression equation)

\begin{tabular}{|c|c|c|c|c|c|c|}
\hline \multirow[b]{2}{*}{ EUC level } & \multirow{2}{*}{$\begin{array}{l}A(8) \\
\left(m \cdot s^{-2} \mathrm{mms}\right)\end{array}$} & \multicolumn{5}{|c|}{ Percentage of forestry workers affected with VWF } \\
\hline & & 10 & 20 & 30 & 40 & 50 \\
\hline $\begin{array}{l}\text { Threshold } \\
\text { Action } \\
\text { Increased risk } \\
\text { Exposure limit value }\end{array}$ & $\begin{array}{l}1 \\
2 \cdot 5 \\
3 \cdot 5^{\star} \\
5\end{array}$ & $\begin{array}{r}22 \cdot 5 \\
9 \cdot 2 \\
6 \cdot 6 \\
4 \cdot 6\end{array}$ & $\begin{array}{r}42 \cdot 9 \\
17 \cdot 5 \\
12 \cdot 6 \\
8 \cdot 9\end{array}$ & $\begin{array}{l}>45 \cdot 0 \\
25 \cdot 5 \\
18 \cdot 3 \\
12 \cdot 9\end{array}$ & $\begin{array}{l}>45 \cdot 0 \\
33 \cdot 3 \\
24 \cdot 0 \\
16 \cdot 9\end{array}$ & $\begin{array}{l}>45 \cdot 0 \\
41 \cdot 1 \\
29 \cdot 5 \\
20 \cdot 8\end{array}$ \\
\hline
\end{tabular}

${ }^{\star}$ Approximated $\mathrm{A}(8)$ value for a short term exposure $(\sim 15 \mathrm{~min})$ to equivalent acceleration of $20 \mathrm{~m} \cdot \mathrm{s}^{-2}$.

$\left.\mathrm{m} \cdot \mathrm{s}^{-2}\right) .^{2122}$ It is worth noting that similar considerations could be applied to the results of our recent survey of stone workers exposed to vibration, in which both the observed prevalence of VWF $(30 \cdot 2 \%)$ and the estimated daily vibration exposure $\left(A(8)=8.4 \mathrm{~m} \cdot \mathrm{s}^{-2}\right)$ were higher than those reported in this study of forestry workers. ${ }^{43}$ These findings suggest a revision of the risk estimates for VWF currently provided by ISO 5349. A new proposal should take into account the changes in vibration exposure that occurred in the industry during the last two decades, as well as the dose-response data reported in the most recent epidemiological studies of worker groups exposed to vibration. ${ }^{43} 46-48$

The results of this study were also used to evaluate the suitability of the vibration exposure levels included in the directive for physical agents proposed by the Commission of the European Union (EU). ${ }^{49}$ Table 8 reports the number of years of vibration exposure that are expected to cause VWF in selected percentiles of a worker population according to the EU vibration levels expressed in terms of $A(8)$. The predicted years of vibration exposure were estimated by the regression equation shown in the figure. According to the widely prevalent opinion among investigators, it seems that the threshold value of $1 \mathrm{~m} \cdot \mathrm{s}^{-2}$ is adequately protective for most of the workers occupationally exposed to hand transmitted vibration. ${ }^{3950}$ As expected, the lifetime exposure period for the onset of VWF decreases with increasing daily vibration exposure. Our data tend to support the various provisions (technical, administrative, and medical) specified in the EU directive for vibration exposure above the action level $\left(2.5 \mathrm{~m} \cdot \mathrm{s}^{-2}\right) .{ }^{49}$ The estimated magnitude of the risk of VWF among workers exposed to eight hour energy equivalent frequency weighted acceleration of 5 $\mathrm{m} \cdot \mathrm{s}^{-2}$ indicates that the value of exposure limit proposed by the EU Commission is not too conservative.

In conclusion, in this study of VWF among forestry workers the estimated dose-response relation suggests a time dependency for cumulative vibration exposure that is consistent with that proposed by current standards for hand transmitted vibration. ${ }^{22} 28$ Owing to both the introduction of preventive measures in forest work and some major differences in the assessment of vibration exposure, the estimated risk of VWF in the study population was found to be lower than that predicted by ISO $5349 .{ }^{22}$ In accordance with other epidemiological reports, our findings tend to support the vibration exposure levels proposed by the EU directive for physical agents. ${ }^{46} 4749$

1 Grounds MD. Raynaud's phenomenon in users of chain saws. Med F Aust 1964;1:270-2.

2 Takamatsu M, Futatsuka M, Sakurai T, Matoba T, Gotoh $\mathrm{M}$, Aoyama $\mathrm{H}$, et al. A study of the extent and scope of local vibration hazards in Japan. Ind Health 1982; 20:177-90.

3 Kylin B, Lidström IM. Vibration disorders in forestry workers. Stockholm: National Institute of Occupational Health, 1970: MF103/70.

4 Laitinen J, Puranen J, Vuorinen P. Vibration syndrome in lumbermen (working with chain saws). $f$ Occup $M e d$ 1974;16:552-6.

5 Turtiainen $\mathrm{K}$. Chain saw operator's opinions of chain saw vibration: a questionnaire study. Work Environ Health 1974;11:132-5.

6 Pyykkö I. The prevalence and symptoms of traumatic vasospastic disease among lumberjacks in Finland: a field vasospastic disease among lumberjacks in Fin

7 Taylor W, Pearson J, Kell RL, Keighley GD. Vibration syndrome in Forestry Commission chain saw operators. Br F Ind Med 1971;28:83-9.

8 Taylor W, Pelmear PL, Pearson J. Raynaud's phenomenon in forestry chain saw operators. In: Taylor $\mathbb{W}$, ed. The vibration syndrome. London: Academic Press, 1974: 121-39.

9 Laroche PG. Traumatic vasospastic disease in chain-saw operators. Can Med Assoc f 1976;115:1217-21.

10 Barnes R, Longley EO, Smith ARB, Allen JG. Vibration disease. Med $\Im$ Aust 1969;1:901-5.

11 Allingham PM, Firth RD. Vibration syndrome. $N Z \mathrm{Med} f$ 1972;76:317-21.

12 Futatsuka $M$, Ueno $T$. Vibration exposure and vibrationinduced white finger due to chain saw operation. $\mathcal{f}$ Occup Med 1985;27:257-64.

13 Futatsuka M, Ueno T, Sakurai T. Cohort study of vibration-induced white finger among Japanese forest workers over 30 years. Int Arch Occup Environ Health 1989;61:503-6.

14 Riddle HFV, Taylor W. Vibration-induced white finger among chain sawyers nine years after the introduction of anti-vibration measures. In: Brammer AJ, Taylor W, eds. Vibration effects on the hand and arm in industry. New York: John Wiley, 1982:169-72.

15 Koskimies K, Pyykkö I, Starck J, Inaba R. Vibration syndrome among Finnish forest workers between 1972 and 1990. Int Arch Occup Environ Health 1992;64:251-6.

16 Takagi S. Raynaud's phenomenon due to chain saw and chipping machine. fpn Circ ₹ 1968;32:99-110.

17 Futatsuka $M$. Studies on vibration hazards due to chain saw. Kumamota Medical fournal 1969;43:467-524. (In Japanese.)

18 Hellstrøm $B$, Lange Andersen $K$. Vibration injuries in Norwegian forest workers. Br f Ind Med 1972;29:255-63.

19 Wakisaka I, Nakano A, Ando M. Raynaud's phenomenon in chain saw operators. Acta Medica Kagoshima 1975;17:1-6.

20 Taylor W, Pelmear PL, Keighley GD. A longitudinal study of Raynaud's phenomenon in chain saw operators. In Wasserman DE, Taylor W, Curry MG, eds. Proceedings of the International Occupational Hand-Arm Vibration of the International Occupational Hand-Arm Vibration Occupational Safety and Health, 1977:69-78. (Publ No 77-170.)

21 Brammer AJ. Relations between vibration exposure and the development of the vibration syndrome. In: Brammer AJ, development of the vibration syndrome. In: Brammer AJ,
Taylor $\mathrm{W}$, eds. Vibration effects on the hand and arm in Taylor W, eds. Vibration effects on the hand and
industry. New York: John Wiley, 1982:283-90.

22 International Organization for Standardization. Mechanical vibration-Guidelines for the measurement and the assessvibration-Guidelines for the measurement and the assessment of human exposure

23 Hempstock TI, O'Connor DE. The measurement of handarm vibration. In: Taylor W, Pelmear PL, eds. Vibration white finger in industry. London: Academic Press, 1975: 111-22. 
24 Pelmear PL, Taylor W, Wasserman DE, eds. Hand-arm vibration - a comprehensive guide for occupational health professionals. New York: Van Nostrand Reinhold, 1992: 201-14.

25 Gemne G, Pyykkö I, Taylor W, Pelmear PL. The Stockholm workshop scale for the classification of coldinduced Raynaud's phenomenon in the hand-arm vibration syndrome (revision of the Taylor-Pelmear scale). Scand $\mathcal{F}$ Work Environ Health 1987;13:275-8.

26 Nielsen SL, Lassen NA. Measurement of digital blood pressure after local cooling. F Appl Physiol 1977;43: pressure

27 International Organization for Standardization. Forestry machinery-Chain saws-Measurement of hand-transmitted vibration. Geneva: ISO, 1986:7505.

28 British Standards Institution. Measurement and evaluation of human exposure to vibration transmitted to the hand. London: BSI, 1987:6842.

29 Griffin MJ. The effects of vibration on health. Southampton: University of Southampton, ISVR Memorandum, 1987:632

30 Hosmer DW, Lemeshow S. Applied logistic regression. New York: John Wiley, 1989.

31 Maclure $M$, Greenland $S$. Tests for trend and dose response: misinterpretations and alternatives. $\mathrm{Am} \mathrm{f}$ Epidemiol 1992;135:96-104.

32 Atkinson AC. Plots, transformations and regression. Oxford: Oxford Sci Publ, 1985:155-83. (Oxford Statistical Science Series 1.)

33 Mirbod SM, Yoshida H, Nagata C, Inaba R, Komura Y, Iwata $H$. Hand-arm vibration syndrome and its prevalence in the present status of private forestry enterprises in Japan. Int Arch Occup Environ Health 1992;64:93-9.

34 Brubaker RL, Mackenzie CJG, Hertzman C, Hutton S, Slakov J. Longitudinal study of vibration-induced white finger among coastal fallers in British Columbia. Scand $\mathcal{f}$ Work Environ Health 1987;13:305-8.

35 Kivekäs J, Riihimäki H, Husman $\mathrm{K}$, Hänninen $\mathrm{K}$, Härkönen $\mathrm{H}$, Kuusela $\mathrm{T}$, et al. Seven-year follow-up of white finger symptoms and radiographic wrist findings in lumberjacks and referents. Scand $\mathcal{F}$ Work Environ Health 1994;20:101-6.

36 Miyashita K, Shiomi S, Itoh N, Kasamatsu T, Iwata H. Epidemiological study of vibration syndrome in response to total hand-tool operating time. $\mathrm{Br} \mathcal{F}$ Ind $\mathrm{Med}$ 1983;40:92-8.

37 Olsen N, Nielsen SL, Voss P. Cold response of digital arteries in chain saw operators. Br F Ind Med 1982;39: 82-8.

38 Olsen N, Nielsen SL. Vasoconstrictor response to cold in forestry workers: a prospective study. $\mathrm{Br}$ F Ind Med 1988; 45:39-42.

39 Griffin MJ. Handbook of human vibration. London Academic Press, 1990.

40 Tasker EG. Assessment of vibration levels associated with hand-held roadbreakers. Scand $\mathcal{f}$ Work Environ Healt 1986;12:407-12.

41 Pelmear PL, Leong D, Wong L, Roos J, Pike M. Hand-arm vibration syndrome and hearing loss in hard rock miners. Fournal of Low Frequency Noise Vibration 1987;6:49-66.

42 Keith SE, Brammer AJ. Rock drill handle vibration: measurement and hazard estimation. Foumal of Sound virement and hazard est 1994;174:475-91.

43 Bovenzi $M$, and the Italian Study Group on Physical Hazards in the Stone Industry. Hand-arm vibration syndrome and dose-response relation for vibration-induced white finger among quarry drillers and stonecarvers. Occup Environ Med 1994;51:603-11.

44 Bovenzi M, Zadini A, Franzinelli A. Vibration-induced vascular disorders in Italian forestry workers. Proceedings of the 23rd International Congress on Occupational Health. Montréal: International Commission on Occupational Health, 1990:87.

45 Gemne G, Lundström R, Hansson JE. Disorders induced by work with hand-held vibrating tools. Solna: National Institute of Occupational Health, Arbete och Hälsa, 1993:6.

46 Brammer AJ. Thresholds for exposure of the hands to vibration. In: Dupuis $\mathrm{H}$, Christ $\mathrm{E}$, Sandover DJ, Taylor
W, Okada A, eds. Proceedings of the 6th International W, Okada A, eds. Proceedings of the 6th International
Conference on Hand-Arm Vibration. Bonn: HVBG,1992: 61-9.

47 Mirbod SM, Inaba $R$, Iwata $H$. A study on the vibrationdose limit for Japanese workers exposed to hand-arm vibration. Ind Health 1992;30:1-22.

48 Nelson CM, Griffin MJ. Comparison of predictive models for vibration-induced white finger. In: Dupuis $\mathrm{H}$, Christ E, Sandover J, Taylor W, Okada A, eds. Proceedings of the 6th International Conference on Hand-Arm Vibration. Bonn: HVBG, 1993:875-83.

49 Council of the European Union. Amended proposal for a council directive on the minimum health and safety requirements regarding the exposure of workers to the risks arising ments regarding the exposure of workers to the risks arising from physical agents-individual directive in relation to Journal of the European Communities, 1994. (94/C Journal of the European Comm

50 Brammer AJ. Threshold limit for hand-arm vibration exposure throughout the workday. In: Brammer AJ, Taylor $\mathrm{W}$, eds. Vibration effects on the hand and arm in industry. New York: John Wiley, 1982:291-9. 